\title{
Assessment of the sorption capacity and regeneration of carbon dioxide sorbents using thermogravimetric methods
}

\author{
Dominika Bukalak • Izabela Majchrzak-Kucęba • \\ Wojciech Nowak
}

Received: 12 October 2012/Accepted: 11 February 2013/Published online: 13 March 2013

(C) The Author(s) 2013. This article is published with open access at Springerlink.com

\begin{abstract}
Adsorption methods using solid sorbents are an alternative to the absorption technology in the processes of purification gases from carbon dioxide. There is a need to rapidly assess the suitability of sorbents for use it in PSA, TSA, or VPSA installations. Important parameters which determine the quality of the sorbent are the sorption capacity of sorbent, selectivity to $\mathrm{CO}_{2}$ and the possibility of regeneration. This paper presents the results of sorption/desorption of $\mathrm{CO}_{2}$ study on the impregnated porous materials using thermogravimetric methods. Thermogravimetry allows for rapid assessment of sorption capacity and regeneration of the sorbents. Specially selected temperature program allowed to determine the sorption capacity of sorbents depending on the concentration of $\mathrm{CO}_{2}$ in the gas mixture and temperature. Degree of sorbent purification was determined in desorption process.
\end{abstract}

Keywords Adsorption - Physicochemical sorbents · Sorption capacity · Thermal analysis

\section{Introduction}

The problem of greenhouse gases emissions has become one of the main priorities of the European Union's energy policy. These gases, such as methane, ozone, and carbon dioxide, are produced naturally and as a result of human activities. The source of $\mathrm{CO}_{2}$ production are mainly

D. Bukalak $(\bowtie) \cdot$ I. Majchrzak-Kucęba · W. Nowak

Faculty of Environmental Engineering and Biotechnology,

Institute of Advanced Energy Technologies, Czestochowa

University of Technology, ul. Dąbrowskiego 73,

42-200 Czestochowa, Poland

e-mail: dbukalak@fluid.is.pcz.pl processes such as coal combustion, generation of electricity and heat. According to the literature [1] $80 \%$ of the world energy supply belongs to fossil fuels, which causes $30 \%$ of anthropogenic carbon dioxide emissions. In recent years, $\mathrm{CO}_{2}$ capture technology has been significantly developed. Currently, it includes the capture of $\mathrm{CO}_{2}$ before combustion, combustion in oxygen-enriched atmosphere, and $\mathrm{CO}_{2}$ capture after combustion.

Separation from flue gases after combustion can take place by adsorption, membrane separation, cryogenic, and currently the most widely used chemical absorption [2]. Membrane separation process involves the use of two types of membranes, the first separator is designed to separate the feed gas stream captured agent, and in the case of adsorption of carbon dioxide membrane passes through the membrane and is then picked up by located on the other side of the adsorption liquid [2].

Cryogenic separation process is compressed and cooled to a suitable temperature and then the separation of gas in a liquid medium. Adsorption using dry sorbents is the physical attraction between the solid surface and the gas. Currently used adsorbents are activated carbon, silica gel, zeolites, synthetic and those derived from fly ash.

In the latter method, chemical absorption, absorption columns are used that are passed through cooled and precleaned exhaust gas. The most common liquid absorbent is monoethanolamine (MEA) [3, 4]. This amine is characterized by a high absorption capacity in relation to $\mathrm{CO}_{2}$. Unfortunately, the process of using amine scrubbers is still very expensive mainly because of the energy intensive process of regeneration of the absorption liquid, corrosive materials, amine degradation, and the need to properly prepare the flue gas before $\mathrm{CO} 2$ sorption [5]. Adsorption using solid sorbents becomes more and more popular. However, solid sorbents are characterized by a lower 
sorption capacity compared to amines solutions. Impregnation of porous materials using amine solutions can help to improve their sorption capacity. Selection of a suitable adsorbent for use in adsorption systems depends on: sorption capacity, the ability to regenerate, the operating window (best adsorption and desorption temperature), profiles of adsorption/desorption, regeneration and stability stages and the kinetics of the adsorption/desorption. This article presents the study of properties of physicochemical sorbents using thermogravimetric methods. Zeolite from fly ash was used in this study to obtain physicochemical sorbent. The aim of this study was zeolite modification with amine solutions for obtaining physicochemical sorbent and determine their sorption capacities and regeneration.

Table 1 Chemical composition of fly ash

\begin{tabular}{|c|c|c|c|c|c|c|c|c|c|c|c|c|}
\hline & \multicolumn{2}{|l|}{ LOI } & \multirow[t]{2}{*}{$\mathrm{SiO}_{2} / \%$} & \multirow[t]{2}{*}{$\mathrm{Fe}_{2} \mathrm{O}_{3} / \%$} & \multirow[t]{2}{*}{$\mathrm{Al}_{2} \mathrm{O}_{3} / \%$} & \multirow[t]{2}{*}{$\mathrm{CaO} / \%$} & \multirow[t]{2}{*}{$\mathrm{MgO} / \%$} & \multirow[t]{2}{*}{$\mathrm{Na}_{2} \mathrm{O} / \%$} & \multirow[t]{2}{*}{$\mathrm{K}_{2} \mathrm{O} / \%$} & \multirow[t]{2}{*}{$\mathrm{Mn}_{2} \mathrm{O}_{3} / \%$} & \multirow[t]{2}{*}{$\mathrm{P}_{2} \mathrm{O}_{5} / \%$} & \multirow[t]{2}{*}{$\mathrm{TiO}_{2} / \%$} \\
\hline & $550{ }^{\circ} \mathrm{C}$ & $800^{\circ} \mathrm{C}$ & & & & & & & & & & \\
\hline Fly ash & 1.11 & 1.26 & 54.77 & 4.46 & 22.56 & 7.9 & 0.66 & 1.78 & 1.09 & 0.16 & 0.004 & 2 \\
\hline
\end{tabular}
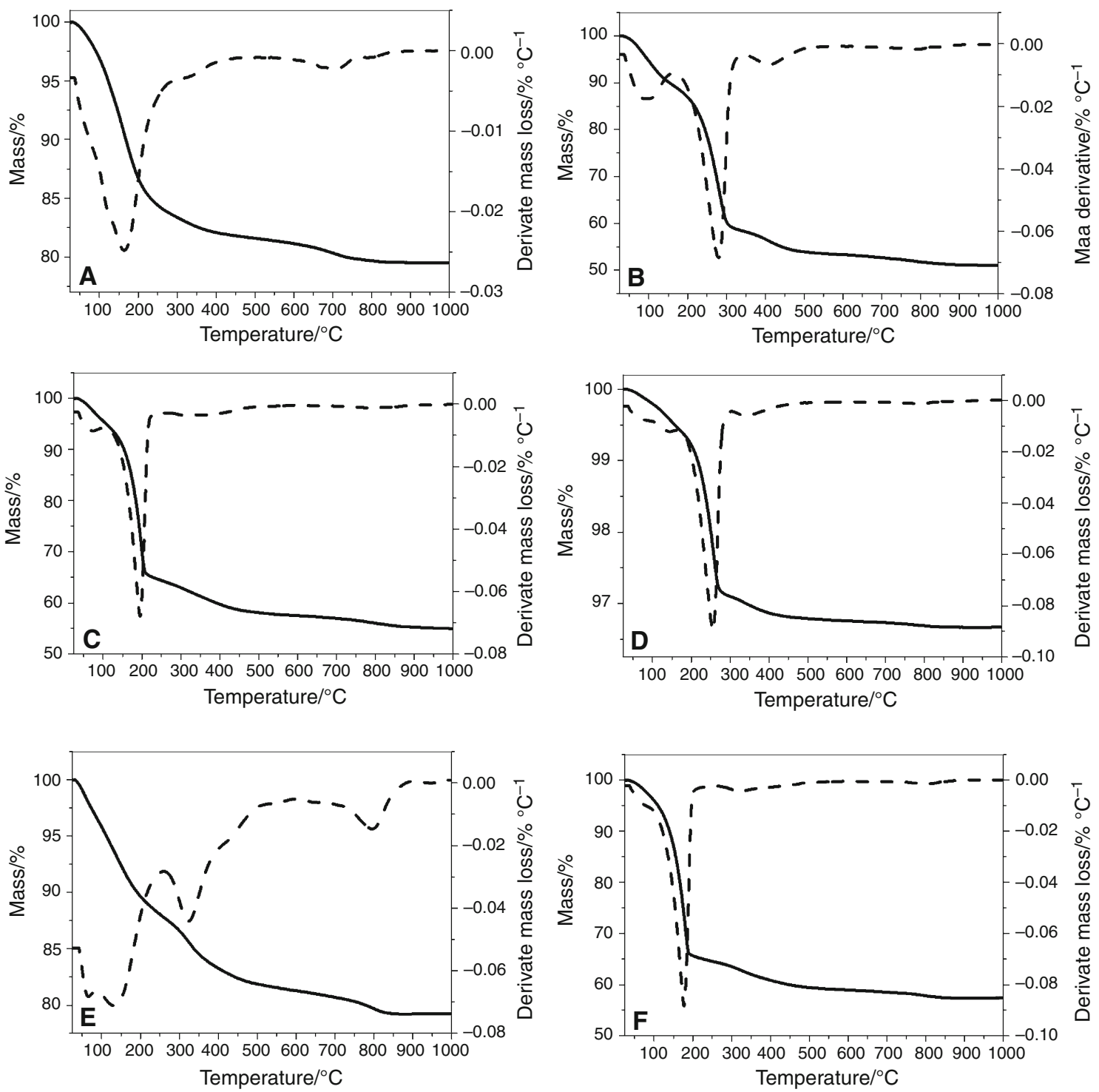

Fig. 1 TG and DTG curves for a Na-X zeolite, b Na-X(PEHA), c Na-X(DEA), d Na-X(TEA), e Na-X(MEA), f Na-X(MDEA) 


\section{Materials and methods}

As a basis to obtain physicochemical sorbent, zeolite from fly ash was used. To obtain zeolite from fly ash, fly ash was mixed with sodium hydroxide in a mass ratio of 1:1.2, then subjected to heat treatment at $550{ }^{\circ} \mathrm{C}$ for $1 \mathrm{~h}$ with heating rate $1{ }^{\circ} \mathrm{C} \mathrm{min}^{-1}$. After cooling to room temperature, the material was milled and mixed with water in a mass ratio 1:4. Mixture was mixed in room temperature for $1 \mathrm{~h}$. Then, the samples were subjected to a temperature of $90{ }^{\circ} \mathrm{C}$ for $24 \mathrm{~h}$. After this time filtered and washed several times with distilled water. The final step was drying the materials in $100{ }^{\circ} \mathrm{C}$ for $24 \mathrm{~h}$. Obtained material was analyzed by XRF analysis. To obtain physicochemical sorbent, base material was impregnated with amine solutions (PEHA: pentaethylenehexamine, DEA: diethanolamine, TEA: triethanolamine, MEA, MDEA: methyldiethanolamine) using wet method of impregnation [6]. Amine solutions were prepared by vigorously mixing the appropriate amounts of solvent and amine. The base material was added to the solution, and then stirred for $30 \mathrm{~min}$ at room temperature. The final step was filtration and drying. Research of sorption-desorption cycles using thermobalance TGA/SDTA 851e were carried out. At temperature-programed adsorption/desorption test sample was heated at $25-100{ }^{\circ} \mathrm{C}$ under nitrogen (heating rate $10{ }^{\circ} \mathrm{C} \mathrm{min}^{-1}$ ) and maintained at this temperature for $15 \mathrm{~min}$ (up to a constant mass of the sample). The sample was then cooled to $25{ }^{\circ} \mathrm{C}$ and the gas bubbled through for $2 \mathrm{~h}$ at a flow of $50 \mathrm{~mL} \mathrm{~min}^{-1}$. The increase of mass during this phase is considered $\mathrm{CO}_{2}$ sorption capacity at this temperature. In the next stage, temperature increased at a rate of $0.25{ }^{\circ} \mathrm{C} \mathrm{min}{ }^{-1}$ from 25 to $100{ }^{\circ} \mathrm{C}$ (to determine the effect of temperature on the sorption capacity of samples). Change in mass during this stage was used to evaluate the effect of temperature on the adsorption of $\mathrm{CO}_{2}$. Adsorption capacity is given in $\mathrm{mg} \mathrm{CO}_{2} \mathrm{~g}^{-1}$ of adsorbent. The last stage of this experimental was desorption in $100{ }^{\circ} \mathrm{C}$. Thermal stability of physicochemical sorbent was also determine and was performed in a nitrogen atmosphere. Appropriate amount of sample was heated with a heating rate $20{ }^{\circ} \mathrm{C} \min ^{-1}$ to temperature $1,000{ }^{\circ} \mathrm{C}$.

\section{Results and discussion}

Fly ash material used for the synthesis of $\mathrm{Na}-\mathrm{X}$ zeolite was characterized by a chemical composition shown in Table 1 .

The main components of fly ash are $\mathrm{SiO}_{2}$ and $\mathrm{Al}_{2} \mathrm{O}_{3}$. According to the standard BN-79/6722-09 material has been classified as silica ash. Due to the high content of silicon and aluminum compounds, fly ash provides an ideal base for the synthesis of zeolites.

$\mathrm{X}$-ray analysis of the zeolite material obtained by modification of the fly ash showed the presence of phase $\mathrm{Na}-\mathrm{X}$. Material obtained on the basis of fly ash was high quality, contains only small quantities of quartz, which is a remnant of the fly ash.

For all samples thermal stability test was carried out. Figure 1 presents the TG and DTG profiles of each sample obtained as a result of the thermal stability test.

As we can see in Fig. 1 each samples was characterized by varying mass loss during the experiment. The individual mass losses correspond to decompose amines contained in the pores of the material and indirect evidence of the lawfulness of the impregnation process. The greatest mass loss was for zeolite from fly ash impregnated with PEHA (B:Na-X(PEHA)). The loss amounted to $48 \%$, whereas pure, untreated zeolite mass loss was $20 \%$. Impregnation adversely reflected by sample modified with TEA and MEA. This is confirmed by the low mass loss $3.5 \%$ for the TEA and $20 \%$ for MEA, respectively. For the remaining samples, mass loss also confirmed the presence of amines.

The next step in the evaluation of the quality of the physicochemical sorbents was to determine their sorption
Fig. 2 Temperature-programed adsorption/desorption test result

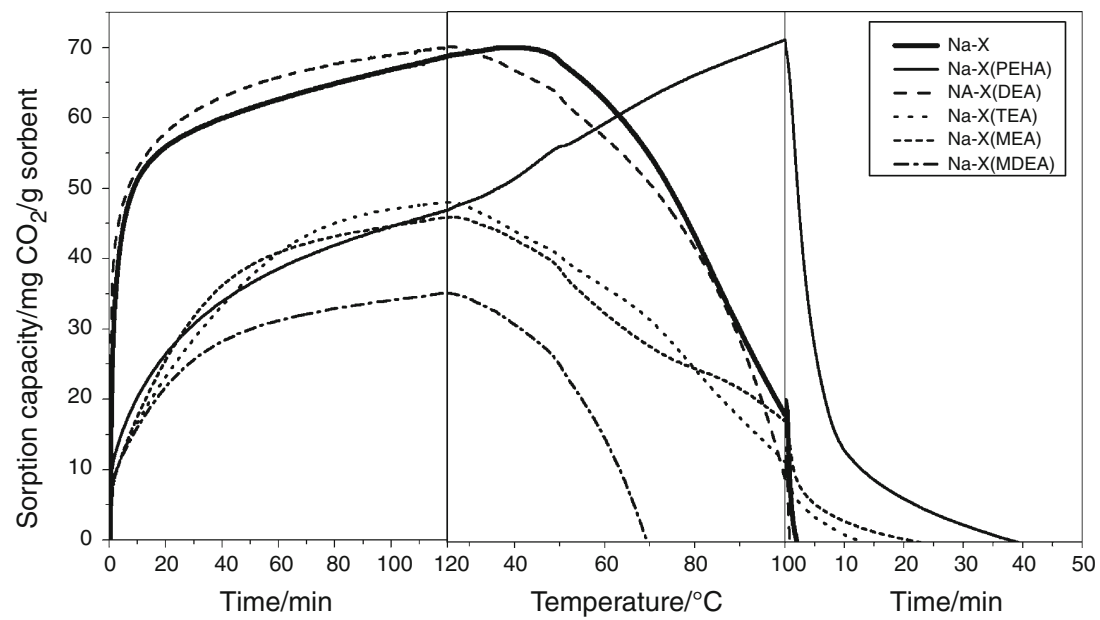


capacity. Figure 2 shows the results of temperature-programed adsorption test.

As we can see in Fig. 2 impregnation using amine solutions have a significant effect on the sorption capacity of tested sorbent. In most case it contributed to sorption capacity reduction. Determination of sorption capacity was held in two stages. In the first stage sorption capacity of sorbents was set at $25{ }^{\circ} \mathrm{C}$. Untreated fly ash zeolite sorption capacity was $60 \mathrm{mg} \mathrm{CO}_{2} \mathrm{~g}^{-1}$ sorbent at this temperature. The highest sorption capacity at $25{ }^{\circ} \mathrm{C}$ was for zeolite impregnated with DEA (Na-X(DEA)). Its sorption capacity was about $1.5 \%$ higher than the sorption capacity of pure zeolite. Na-X(PEHA), Na-X(TEA), Na-X(MEA), and Na-X(MDEA) materials have lower sorption capacities than pure $\mathrm{Na}-\mathrm{X}$ at $25{ }^{\circ} \mathrm{C}$ and it was $47,48,46$, and $35 \mathrm{mg}$ $\mathrm{CO}_{2} \mathrm{~g}^{-1}$ sorbent, respectively. This was sorption capacity at $25{ }^{\circ} \mathrm{C}$ after $2 \mathrm{~h}$.

In the second stage, the sorption temperature was increased. Low heating rate allows to determine the effect of temperature on the sorption capacity of the materials tested. Sorption capacity of physical adsorbent $(\mathrm{Na}-\mathrm{X})$ is the highest at $40{ }^{\circ} \mathrm{C}$ and then rapidly decreases with increasing temperature. The observed trend is the result of physical adsorption of $\mathrm{CO}_{2}$ which takes place in this case, and which is highly temperaturedependent, decreasing significantly with its growth. In higher temperature it can be observed higher sorption capacity of zeolite material obtained from fly ash modified with PEHA. The sorption capacity of this material (Na-X(PEHA)) at $100{ }^{\circ} \mathrm{C}$ is about $75 \%$ higher than for untreated material at the same temperature. For other materials, the sorption capacity increases with decreasing temperature. In comparison to the sorption capacity at $25^{\circ} \mathrm{C}$, sorption capacity decreased by $88 \%$ for Na-X(DEA), $78 \%$ for Na-X(TEA), and $65 \%$ for $\mathrm{Na}-\mathrm{X}(\mathrm{MEA})$ at $100{ }^{\circ} \mathrm{C}$. For MDEA modification sorption capacity decreased rapidly at $70{ }^{\circ} \mathrm{C}$. The studies of desorption showed complete desorption of $\mathrm{CO}_{2}$. There are studies in which the impregnation of $13 \mathrm{X}$ zeolite material with MEA solution helped to improve the sorption properties of the material [7]. In conducted study [7], a different method of impregnation of zeolite $13 \mathrm{X}$ was used. In Chatti et al.'s [7] research another form of zeolite was used. He use 13X zeolite beads as a matrix. In this study, Na-X zeolite powder was used.

In summary, there is a need to select a suitable method of impregnation. The study on fly ash-based physicochemical sorbent showed that the MEA impregnation did not bring the expected result. But it should be noted that the studies were carried out on material obtained by synthesis from fly ash. The properties of this material are different than for commercial. Materials obtained by a synthesis from fly ash are characterized by a sorption capacity lower than those obtained with commercially pure chemical ingredients. Impregnation using properly selected amines and impregnation procedure helps to improve properties of materials derived from fly ash. This contributes to improving the quality of sorbent. In the future, zeolites from fly ash impregnated with amines may become competitive for commercial materials. Through the use of a porous substrate from residual fly ash from power plants we can reduce the production costs of sorbent.

\section{Conclusions}

Based on the study it can be stated that the appropriate selection of impregnation and impregnation methods can contribute to the improvement of sorption properties of porous materials. Impregnation process can help to improve the sorption properties of the material up to $75 \%$ in $100{ }^{\circ} \mathrm{C}$, as was for PEHA impregnation. Research carried out at $25^{\circ} \mathrm{C}$ also confirmed effectiveness of the impregnation of the sample modified with DEA. In literature there is no information about research on impregnated zeolites from fly ash. The studies of adsorption/desorption on the adsorbents showed complete desorption of $\mathrm{CO}_{2}$, which confirmed the reversible nature of the process and the ability to use in multiple cycles. Preliminary evaluation of these parameters can be made using thermogravimetric methods that are fast and useful tool to determine the sorption capacity and the particular profiles of adsorption/ desorption of the selected adsorbent.

Acknowledgments Scientific work was supported by the National Science Centre (Poland), as Project Investigations of $\mathrm{CO}_{2}$ adsorption/ desorption on amine-impregnated fly ash-derived zeolites (7506/B/ T02/2011/40). The authors are grateful for this support.

Open Access This article is distributed under the terms of the Creative Commons Attribution License which permits any use, distribution, and reproduction in any medium, provided the original author(s) and the source are credited.

\section{References}

1. $\mathrm{CO}_{2}$ emissions from fuel combustion highlights (2012 edition). Paris: International Energy Agency; 2012.

2. Kotowicz J, Janusz K. Sposoby redukcji emisji $\mathrm{CO} 2$ z procesów energetycznych. Rynek Energii. 2007;1:10-8.

3. Amines used in $\mathrm{CO}_{2}$ capture-health and environmental impacts. Oslo: The Bellona Foundation; 2009.

4. Goto K, Okabe H, Shimizu S, Onada M, Fyjioka Y. Evaluation method of novel absorbents for $\mathrm{CO}_{2}$ capture. Energy Procedia. 2009;1:1083-9.

5. Metz BD, De Coninck O, Loos HC, Meyer LA. Special report on carbon dioxide capture and storage. 2005.

6. Xu X, Song CH, Andersen JM, Miller BG, Scaroni A. Preparation and characterization of novel $\mathrm{CO}_{2}$ "molecular basket" adsorbents based on polymer-modified mesoporous molecular sieve MCM-41. Microporous Mesoporous Mater. 2003;62:29-45.

7. Chatti R, Bansiwal AK, Thote JA, Kumar V, Jahav P, Lokhande SK, Biniwale RB, Labhsetwar NK, Rayalu SS. Amine loaded zeolites for carbon dioxide capture: amine loading and adsorption studies. Microporous Mesoporous Mater. 2009;121:84-9. 